\title{
Modeling the economic growth of Arctic regions in Russia
}

\author{
N. Didenko ${ }^{1} \&$ K. Kunze ${ }^{2}$ \\ ${ }^{1}$ St. Petersburg Polytechnic University, Russia \\ ${ }^{2}$ University of Colorado, USA
}

\begin{abstract}
The Russian Arctic zone includes nine regions. These regions are rich in natural resources including fish, timber, and minerals. This distant periphery of Russia is a huge territory and poorly developed. These regions are characterized by the highest gross regional product per capita in the country. In some regions, the industrial sector is powerful, but the social infrastructure is poorly developed. Agriculture is almost absent. In this paper the economic growth in the regions of the Russian Arctic is modeled and factors affecting the economic growth are analyzed. The gross regional product of all nine regions of the Russian Arctic as a percentage of Russia's gross domestic product is used as dependent variable (endogenous variable) in the model. The value of the dependent variable in the current period can be influenced by both its value in the past periods and current and lagged values of exogenous factors. Considering the process of economic growth and analysis of the factors affecting economic growth in regions of the Russian Arctic, autoregressive distributed lag model is used. Using ordinary least squares the coefficients of the model are estimated and findings about the impact of each of the five exogenous factors on the dependent variable are presented.

Keywords: Russian Arctic, economic growth in the regions, gross regional product, endogenous variable and exogenous factors, autoregressive distributed lags, stationary series, ordinary least squares.
\end{abstract}

\section{Introduction}

The northern territory of Russia is one of the richest regions in Russia. Oil, gas, gold, diamonds, nickel, copper, apatite, platinum, iron, as well as timber, fish, furs, fertilizers, and more make it extremely important for the economy of the 
country. Almost $100 \%$ of proven reserves of nickel, cobalt, tantalum, tin, niobium and rare earth metals are concentrated in the Russian Arctic. According to statistical data, the total value of all minerals in Russia is more than \$28 trillion. $80 \%$ of this amount are contained in the northern region.

Russian North accounts for $20 \%$ of the gross domestic product of Russia, $60 \%$ of Russia's commodity exports, $95 \%$ of Russian gas production, while less than $10 \%$ of the Russian population lives in these regions [1-5].

Not only most of the country's natural resources are located in the Northern Regions, but also the shortest route from Europe to the Asia-Pacific region runs through these regions. Russian Arctic zone can act as a bridge between East and West.

The aim is to study the features of socio-economic development of the northern territories of Russia, using the procedure of modeling the economic growth of regions of the Russian Arctic and analyzing the factors affecting the economic growth.

\section{First stage of modeling: formulation of the problem and characteristics of the Arctic zone}

Formulation of the problem is characterized by the three main points: description of the problem, determination of the purpose of modeling, and presentation of the analysis of the object or modeling process.

The main issue by formulating the problem is to determine the object of modeling and understand what the goal of formulation should be. The object of modeling in this case is the region, and the purpose of the simulation-analysis is the relationship of economic growth of regions in the Russian Arctic and factors affecting the economic growth. Characteristics of the object are outlined by the description of Arctic Zone in context of indicators that are considered in the stages of modeling [6].

Arctic Zone is a distal peripheral raw material region that is weakly developed. It is characterized by huge natural resources, large-scale industry with practically no productive agriculture, poor infrastructure, and very low developed housing and communal services. The population has adapted to the harsh local nature. Regions contain small number of inhabitants that are faced by poor health and unstable family relationships. Therefore the main rout of development is the improvement of infrastructure, enhancement of living conditions of the population, and organization of tourism.

Evaluation of the regions is generally based on the indicators that can be divided into four groups - natural environment, social infrastructure, personal development, and production sphere.

Natural environment includes resource stocks (taking into account the possibilities of their use), distribution of oil, natural gas, coal and gold in Russia's regions. Social infrastructure discusses the development of infrastructure, density of railway roads, paved roads, telephones in rural and urban areas, and the commissioning of residential buildings (sq. meters per capita). Personal development contains infant mortality, unemployment, 
morbidity, welfare, a number of indicators on income, cost of living, the average prices in the housing market, standards of living, human development index (HDI), life expectancy, and number of doctors. Production sphere examines the dynamics of specialization, structure of industrial production, comparison of gross regional product (GRP) of Arctic Zone to GRP of Russian Federation as a whole, the degree of specialization, economic potential, cost of fixed assets (million rubles per capita), gross regional product per capita, investment in fixed capital per capita, share of exports in gross regional product, and foreign investments (weighted average for the years) as a percentage of GRP.

\section{Second stage of modeling: purpose of modeling, choice of endogenous and exogenous variables, and estimation of the model}

Defining the purpose of modeling involves answering the following questions: Why is this process modeled? What will show the model? Furthermore defining the purpose of the model allows estimating the model easier. Without framing the goal of the model the process of modeling will be unproductive in nature. The model is created to answer a set of questions. These questions should be formulated in advance representing the basis for determining the purpose of modeling. The main overall objective of the simulation is to monitor the system exposed to external or internal factors. The purpose of our presentation is a study of the effects of several independent variables on the dependent variables and the prediction of the dependent variables with the help of independent variables.

The following indicators were considered as dependent variables (endogenous model parameters) within the model of economic growth in regions of the Russian Arctic Zone:

$y_{t}^{1} \quad$ Fraction of gross regional product of the Arctic Zone in Russia's gross domestic product in year $\mathrm{t}$;

$y_{t}^{2} \quad$ Fraction of gross regional product of Russian Arctic in Russia's total gross regional product in year $\mathrm{t}$;

$y_{t}^{3} \quad$ Fraction of output produced in the Arctic zone in Russia's total goods manufactured in year $\mathrm{t}$;

$y_{t}^{4 i} \quad$ Fraction of output in each region of the Russian Arctic in Russia's total goods manufactured (where $\mathrm{i}=1.2, \ldots, 8$ (region number)) in year $\mathrm{t}$.

The following exogenous variables were chosen:

$y_{t-1}^{1}, y_{t-2}^{1}, y_{t-3}^{1} \quad$ Fraction of gross regional product of the Russian Arctic in Russia's gross domestic product for the periods prior to year t;

$y_{t-j}^{2} \quad$ Fraction of gross regional product of Russian Arctic in the

Russia's total gross regional product for the periods prior to year t; 
$y_{t-j}^{3}$

$y_{t-1}^{4 i}, y_{t-2}^{4 i}, y_{t-3}^{4 i}$

$x_{t}^{1}, x_{t-1}^{1}, x_{t-2}^{1}, x_{t-3}^{1}$

$x_{t}^{2}, x_{t-1}^{2}, x_{t-2}^{2}, x_{t-3}^{2}$

$x_{t}^{3}, x_{t-1}^{3}, x_{t-2}^{3}, x_{t-3}^{3}$

$x_{t}^{4}, x_{t-1}^{4}, x_{t-2}^{4}, x_{t-3}^{4}$

Fraction of manufactured products in the Arctic zone of Russia in total Russian production produced prior to year t; Fraction shipped from i-th region of the Arctic zone in total products shipped from Russia for periods prior to year $t$;

Payment received for the import of technology and technical services in regions of the Arctic zone of the Russian Federation;

The average labor productivity in regions of the Arctic zone of the Russian Federation;

Average annual salary in regions of the Arctic zone;

Number of doctors per 10,000 people in regions of Russian Arctic.

For the simulation of economic growth in the region of Russian Arctic and analysis of factors affecting the economic growth, a time series model is used. Thereby an autoregressive distributed lags model is implemented (ADL-model). This model sets the current value of the endogenous variable in relation to past values of the series of the same variable and to current and past values of time series of other variables.

Consider the following general form ADL model:

$$
y_{t}=\sum_{i=1}^{k_{1}} \alpha_{i} y_{t-i}+\sum_{i=1}^{k_{2}} \alpha_{i} x_{t-i}^{1}+\sum_{i=1}^{k_{3}} \alpha_{i} x_{t-i}^{2}+\sum_{i=1}^{k_{4}} \alpha_{i} x_{t-i}^{3}+\sum_{i=1}^{k_{5}} \alpha_{i} x_{t-i}^{4}
$$

\section{The main steps of simulation}

The modeling procedure involves the following steps:

a. Determining the goal of the model.

b. Selection of endogenous and exogenous parameters and model type.

c. Formation of the series of endogenous and exogenous parameters.

d. Checking the autocorrelation of endogenous and exogenous parameters to select the lag, which should have a strong correlation with the value of the parameter of the preceding period. Testing the significance of the autocorrelation coefficients using Box-Pearson criterion.

e. Checking exogenous parameters for multicollinearity. Exclusion from further analysis of one of the indicators of a pair of indicators, if the correlation coefficient between them is high.

f. Checking the time series for stationarity using the Dickey-Fuller test. In case of non-stationary, transformation to a stationary time-series.

g. Building ADL model for new stationary series in case of non-stationary.

h. Finding the coefficients of the model using regression analysis.

i. Formulation of conclusions. 


\section{Modeling the economic growth in eight regions of the Russian Arctic and analysis of factors affecting the economic growth in these regions}

The model is constructed according to the previously mentioned procedure. As the endogenous variable the fraction of gross regional product of the Arctic Zone in Russia's gross domestic product in year has been used. The following exogenous variables have been used:

$x_{t}^{1}, x_{t-1}^{1}, x_{t-2}^{1}, x_{t-3}^{1}$ - Payment received for the import of technology and technical services in regions of the Arctic zone of the Russian Federation;

$x_{t}^{2}, x_{t-1}^{2}, x_{t-2}^{2}, x_{t-3}^{2}-$ The average labor productivity in regions of the Arctic zone of the Russian Federation;

$x_{t}^{3}, x_{t-1}^{3}, x_{t-2}^{3}, x_{t-3}^{3}$ - Average annual salary in regions of the Arctic zone;

$x_{t}^{4}, x_{t-1}^{4}, x_{t-2}^{4}, x_{t-3}^{4}-$ Number of doctors per 10,000 people in regions of Russian Arctic.

Data for all variables used in the analysis has been retrieved from the database of regional branches of the State Statistics Committee of Russia [7-9].

Autocorrelation analysis shows that the first lag has the strongest correlation with the last period. To test the significance of the autocorrelation coefficients criterion of Boxing-Pearson has been used [10]. All lag coefficients are considered as significant at the conventional level. Q-statistic $=\{5.89804202$; $7.671768915 ; 8.385738346 ; 8.57686292 ; 6.232739376\}$. For the significance level $\alpha=0,05$ and number of degrees of freedom $\mathrm{k}=1$, the critical value of $\chi^{2}$ is 3.8 .

Checking exogenous parameters for multicollinearity shows that the correlation coefficients between the indicators are not high. Thus the correlations between the parameters not high enough and further exclusion of one of the variables is not necessary. Further analysis was conducted including all independent variables.

The test of the time-series for stationarity revealed that it is not stationary, as there is no rapid decay of the autocorrelation coefficients to zero. Ranks were brought to a stationary form by calculating the difference with the figure of the previous period. An ADL-model for new stationary series has been constructed as follows:

$$
\Delta y_{t}=\sum_{i=1}^{k_{1}} \alpha_{0} \Delta y_{t-i}+\sum_{i=1}^{k_{2}} \alpha_{1} \Delta x_{t-i}^{1}+\sum_{i=1}^{k_{3}} \alpha_{2} \Delta x_{t-i}^{2}+\sum_{i=1}^{k_{4}} \alpha_{3} \Delta x_{t-i}^{3}+\sum_{i=1}^{k_{5}} \alpha_{4} \Delta x_{t-i}^{4}
$$

$k_{1}, k_{2}, k_{3}, k_{4}, k_{5}-$ Number of lags of each of the five exogenous variables;

$\Delta x_{t}^{1}, \Delta x_{t}^{2}, \Delta x_{t}^{3}, \Delta x_{t}^{4}-$ Differences between year $t$ and $t-1$ of exogenous indicators.

Given the number of lags of the dependent variable and influencing variables, ADL model takes the form:

$$
\Delta y_{t}=\alpha_{0} \Delta y_{t-1}+\alpha_{1} \Delta x_{t}^{1}+\alpha_{2} \Delta x_{t-1}^{1}+\alpha_{3} \Delta x_{t}^{2}+\alpha_{4} \Delta x_{t-1}^{2}+\alpha_{5} \Delta x_{t}^{3}+\alpha_{6} \Delta x_{t-1}^{3}+\alpha_{7} \Delta x_{t}^{4}+\alpha_{8} \Delta x_{t-1}^{4}
$$


Using regression analysis coefficients in the model are found:

$$
\begin{aligned}
& \Delta y_{t}=-0,16927+3,449788 \Delta y_{t-1}+0,000776 \Delta x_{t}^{1}+0,000603 \Delta x_{t-1}^{1}+0,015269 \Delta x_{t}^{2} \\
&-0,02788 \Delta x_{t-1}^{2}-9,5 E-0,6 \Delta x_{t}^{3}+1,64 E-0,5 \Delta x_{t-1}^{3}+2,405838 \Delta x_{t}^{4}-0,24925 \Delta x_{t-1}^{4} \\
& \mathrm{R}^{2}=0.720774, \mathrm{~F}_{\phi}(0.947496) \geq F_{\text {crit. }}(0,240274) .
\end{aligned}
$$

The coefficients of the regression equation are insignificant in the following exogenous variables: import of technologies for the period $t-1$, labor productivity in period $t$ and $t-1$, and the wages for the period $t$.

\section{Conclusion}

The modeling procedure can be summarized as follows. After stating the problem, the goal of the simulation, and the characteristics of the object of the model, using data the model is constructed in the form of a linear equation and the coefficients are found.

Knowing the specific type of the model one can make certain findings. For example, exogenous parameters describing innovation and technological sphere have a directly proportional impact on the economic growth in the Arctic Zone. Indicators of social sphere have an inversely proportional impact on the endogenous parameter. In other words, the simulation can provide a variety of information for better understanding of the analyzed object or process.

\section{Acknowledgement}

This paper is based on research carried out with the financial support of the grant of the Russian Scientific Foundation (Project No. 14-38-00009). St. Petersburg Polytechnic University.

\section{References}

[1] Istomin A., Pavlov K., \& Célin V. Ekonomika of the Arctic zone of Russia//Society and economy, 7, pp. 158-172, 2008.

[2] About a condition and use of mineral raw material resources of the Russian Federation in 2002. Online. http://docs.cntd.ru/document/ 901911655.

[3] Ore mineral resources of the Russian Arctic, 2007. Online. http://рустрана.pф/article.php?nid=19352.

[4] Satarov G., Artoboleeskiy S., Smirnyagin L. et al. Space of the northern territories. Online. http://narfu.ru/www.pomorsu/mba/.

[5] Pilyasov A. And the last will become the first: The northern periphery on the way to knowledge economy. M, Book house of LIBROKOM, 2009.

[6] Kozlov A., Gutman S., \& Zaychenko I. Theoretical and methodological fundamentals of concept of complex regional indicators for development of Arctic Zone of Russian Federation//The strategic priorities of development of the Russian Arctic: Collection of scientific works/Under 
the editorship of V.V. Ivanter.-Moscow: Science Publishing House, pp. 103-112, 2014.

[7] Regions of Russia. Socio-economic indexes. 2011: Statistical collection. Rosstat. M, 2012.

[8] Regions of Russia. Socio-economic indexes. 2010: Statistical collection. Rosstat. M, 2011.

[9] Regions of Russia. Socio-economic indexes. 2009: Statistical collection. Rosstat. M, 2010.

[10] Wooldridge, J.M. Introductory Econometrics. A Modern Approach-4 Ed. Cengage Learning; International Ed., 2009. 